Brit. J. prev. soc. Med. (1974), 28, 258-264

\title{
Programmes for the prevention of rubella during pregnancy by active immunization
}

\author{
D. S. FREESTONE \\ Department of Clinical Immunology, The Wellcome Research Laboratories, Beckenham, Kent
}

\begin{abstract}
SUMmaRY
United Kingdom and United States programmes of active immunization for the prevention of rubella during pregnancy are compared and their respective advantages and disadvantages discussed. The need for revaccination is more likely to arise with the United States programme in which young children are vaccinated and where, in future, immunity in adults will become increasingly vaccine-induced.
\end{abstract}

\section{INTRODUCTION}

In nearly all developed countries $15-20 \%$ of women are still susceptible to rubella when they reach child-bearing age despite widespread endemic infection among children between the ages of 5 and 10 years (Field, 1967; Rawls et al., 1967; Cockburn, 1969). It has been estimated that over 30,000 infants with congenital rubella were born in the United States during 1964-65 as a consequence of maternal infection (Cooper et al., 1969). Notifications since then have been between 10 and 77 cases per annum for the years 1966-73 (Figure). In the United Kingdom, statistics on the occurrence of rubella and congenital rubella are not readily available since rubella is not a nationally notifiable disease and a scheme for surveillance for congenital rubella has only recently been established. The preliminary report of the first year's operation of the National Congenital Rubella Surveillance Programme (Dudgeon et al., 1973) indicates that the estimate that 200-250 affected infants are born annually in non-epidemic years is approximately correct. Although it is probably an artefact of the reporting systems it is of interest that in the United Kingdom the incidence appears to be several-fold greater than in the United States regardless of population differences between the two countries.

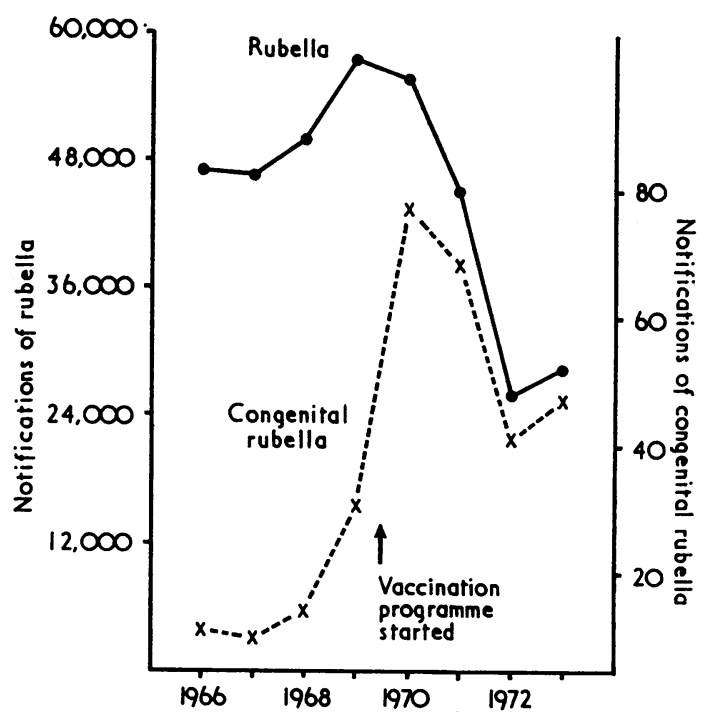

FIGURE United States notifications for rubella and congenital rubella 1966-73 (Data from CDC Annual Supplement, 1972. Morbidity and Mortality Reports, 1973, 22, 439).

In tropical areas rubella usually occurs early in life with the result that nearly all children have been infected before they are adolescent. Consequently congenital rubella is apparently rare although statistics are not usually available (Saidi, 1972). In contrast, in other communities, including many islands with tropical climates and those separated from the rest of the world by poor transport connections, there are periods of high population susceptibility which alternate with large outbreaks of rubella and periods of immunity (Judelsohn and Wyll, 1973). 
TABLE I

TOTAL LIVE BIRTHS FOR ONE YEAR IN ENGLAND AND WALES AND USA BY AGE OF MOTHER AT BIRTH*

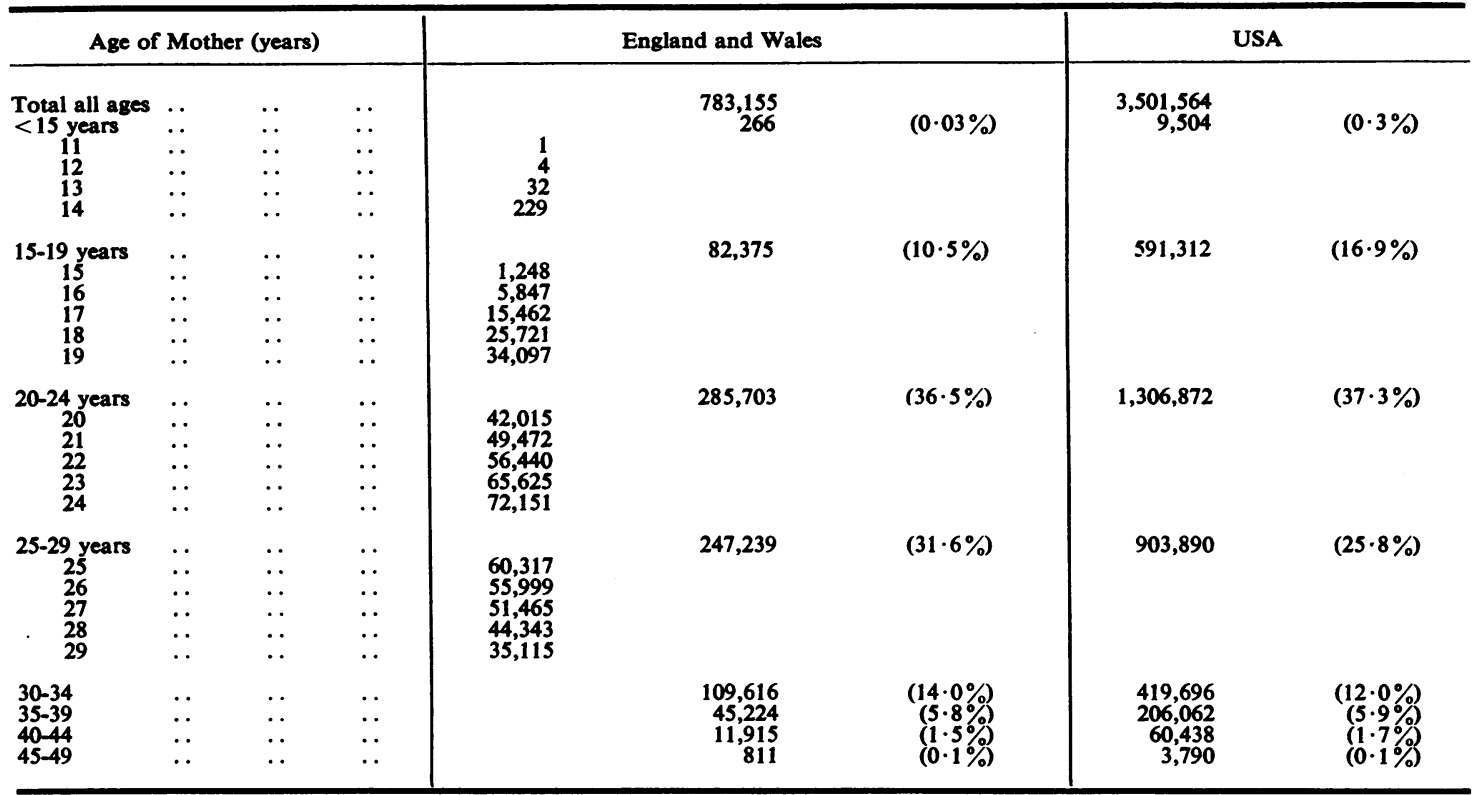

*From the Registrar General's Statistical Review of England and Wales for 1971, Part II. HMSO, London, 1973.

Vital Statistics of the United States, 1968, Volume 1, Natality US Department of Health Education and Welfare-Public Health Service.

RECOMMENDATIONS FOR VACCINATION AGAINST RUBELlA-UNITED KINGDOM

In the United Kingdom and many European countries, the principal aim of vaccination is to ensure that women are individually immune to rubella when childbearing. Thus the Department of Health and Social Security (1972) recommend vaccination of girls between their 11th and 14th birthdays. In this age group live births are uncommon, only 37 being recorded in England and Wales during 1973 (Table I). Although between $50 \%$ and $80 \%$ of girls will be naturally immune at this age, it is administratively simpler to offer vaccination to all than initially to screen them for antibody. This eliminates such problems as what antibody level to accept as an indication of immunity and the risk that an incorrect report may lead to failure to offer vaccination to susceptible girls. In addition, low titres of antibody resulting from natural infection early in life may be boosted. In England over 750,000 doses of rubella vaccine have been administered under the auspices of local authorities during the years 1970-72 inclusive (Department of Health and Social Security, 1971-73).

The disadvantage of the British scheme is that it will be several years before vaccination can exert any noticeable effect on the incidence of congenital rubella since about 10 years elapse between the age of vaccination and that of peak childbearing at 24 years (Table I). In the future it may prove important that $47 \%$ of births are to women under the age of 25 years and thus that almost half the children will be born within about 12 years of vaccination of their mothers. Since natural rubella will continue to infect males and girls under the age of 11 years, susceptible adult women will still be exposed to rubella. The use of facilities for laboratory investigation leading in a proportion of cases to termination of pregnancy will not therefore decline in the immediate future. Despite vaccination, therefore, in the immediate future infants with congenital rubella will continue to be born although the numbers should start to fall as the percentage of vaccinated girls in the childbearing years increases.

\section{RECOMMENDATIONS FOR VACCINATION AGAINST Rubella-United States}

In the United States the aim of active immunization is to reduce the incidence of rubella, thus shielding pregnant women from infection (United States Department of Health, Education, and Welfare, 1972). This programme involves the 
vaccination of all children between the ages of 1 and 11 years. The strategy is to supplant transmissible infection with controlled non-transmissible infection by vaccine virus. In establishing this type of programme in 1969, the United States Public Health Advisory Committee on Immunization Practices were no doubt conscious of the epidemiology of rubella in the United States, which indicated that large outbreaks occurred about every seven years, and thus a further outbreak was anticipated in 1971.

It has been estimated that approximately 45 million doses of rubella vaccine have been administered during the four years from June 1969 , of which over 32 million doses were in public vaccination programmes (Krugman and Perkins, 1973; United States Department of Health, Education, and Welfare, 1973). In many States vaccination against rubella is obligatory before school entry. Since vaccine is given early in life most children vaccinated against rubella in the United States will not have been immune before vaccination. Widespread vaccination of this rubellasusceptible section of the population will have greatly reduced the incidence of natural rubella in number of pregnant women exposed to infection. High levels of herd immunity, however, did not prevent the spread of rubella in institutionalized children (Farquhar, 1973), military recruits (Horstmann et al., 1970a; Lehane, Newberg, and Beam, 1970; Vesikari, 1972) or open communities (Klock and Rachelefsky, 1973). In apparent failures of herd immunity to prevent spread of infection, the percentage of the population in whom antibody was induced by vaccine as compared to natural infection may be important.

The quality of the immune responses elicited by the available strains of vaccine appears to be inferior to that resulting from natural infection (Davis et al., 1971; Evans, Niederman, and the community and consequently reduced the

Sawyer, 1971; Wilkins, Leedom, Portnoy, and Salvatore, 1969; Chang, Desrosiers, and Weinstein, 1970; Horstmann et al., 1970a; Lehane et al.,1970)(Table II). This is reflected in investigations which have shown that between $22 \%$ and $80 \%$ of subjects vaccinated with the Cendehill and HPV 77 DE 5 strains may, within a short time of vaccination, exhibit evidence of asymptomatic reinfection on exposure to natural or artificial challenge. These percentages contrast with reinfection rates of less than $6 \%$ in those naturally immune. Following reinfection, in addition to significant increases in antibody titre, a proportion of subjects shed virus, so the infection may be transmissible. Since asymptomatic reinfection may occur in a high percentage of subjects within a short time of vaccination it is possible that later reinfection might be associated with symptomatology and viraemia. The protection derived by the fetus as a result of childhood vaccination of the mother may therefore be less than absolute.

\section{Vaccination of Adult Females}

Both in the United States and in the United Kingdom there are recommendations for the vaccination of certain categories of adult femaleso who have been shown to be susceptible to rubella by prior serological testing. Since live attenuatedo vaccine virus may exhibit the teratogenic and embryotoxic properties of the parent virus, vaccination of adults can only be carried out if it is possible to ensure that women are not pregnant at the time of vaccination and will not become pregnant for at least eight weeks afterwards. The administration of vaccine to adult females without prior serological screening is to be avoided since, for the majority, vaccine is needlessly administered, and if the woman becomes pregnant there are difficulties in determining retrospectively whether

TABLE II

SUBJECTS DEMONSTRATING EVIDENCE OF RUBELLA REINFECTION ON EXPOSURE TO NATURAL OR ARTIFICIAL CHALLENGE

\begin{tabular}{|c|c|c|c|c|c|c|c|}
\hline \multirow[b]{2}{*}{$\begin{array}{l}\text { Horstmann et al. (1970a) } \\
\text { Vesikari (1972) } \\
\text { Evans et al. (1971) } \\
\text { Davis et al. (1971) } \\
\text { Wilkins et al. (1969) } \\
\text { Chang et al. (1970) } \\
\text { Plotkin et al. (1973) } \\
\text { (collected results) }\end{array}$} & & \multicolumn{2}{|c|}{$\begin{array}{c}\text { Vaccine-induced Antibody- } \\
\text { Strains other than Wistar } \\
\text { RA 27/3 }\end{array}$} & \multicolumn{2}{|c|}{ Naturally induced Antibody } & \multicolumn{2}{|c|}{$\begin{array}{l}\text { Wistar RA 27/3 Strain Induced } \\
\text { Antibody }\end{array}$} \\
\hline & $\begin{array}{l}. \\
\because \\
\because \\
\because \\
.\end{array}$ & $\begin{array}{c}12 / 15 \\
\overline{5 / 22} \\
12 / 24 \\
4 / 9\end{array}$ & $\begin{array}{c}(80 \%) \\
\overline{-} \\
(22.7 \%) \\
(50 \%) \\
(44.4 \%)\end{array}$ & $\begin{array}{c}5 / 149 \\
15 / 255 \\
8 / 192 \\
1 / 66 \\
=\end{array}$ & $\begin{array}{l}(3.4 \%) \\
(5.9 \% \\
(4.2 \%) \\
(1.5 \%) \\
=\end{array}$ & $17 / 104$ & $(16 \cdot 3 \%)$ \\
\hline Total &.. & $33 / 70$ & $(47 \cdot 1 \%)$ & $29 / 662$ & $(4 \cdot 3 \%)$ & $17 / 104$ & $(16 \cdot 3 \%)$ \\
\hline
\end{tabular}


she was initially susceptible or immune and, therefore, whether or not termination of pregnancy is indicated. Some authorities limit vaccination to women who are seronegative, while others include also those with low titres of antibody which can be expected to show fourfold or greater increases in titre following vaccination. Clearly, in these circumstances, mass vaccination of adult females cannot be considered since even with the present limited programmes there are several reports of inadvertent vaccination in pregnancy, some of which have been associated with recovery of vaccine virus from fetal tissue and products of conception (Phillips, Maeck, Rogers, and Savel, 1970; Vaheri et al., 1972; Wyll and Herrmann, 1973).

In an attempt to circumvent this difficulty vacination in the postpartum period has been recommended (Horstmann, Liebhaber, and Kohorn, 1970b; Tobin, 1971; Beazley, Hurley, Middlebrook, and Rumpus, 1971). It has the attraction that women may be conveniently screened antenatally and susceptibles vaccinated after delivery. However, it is not entirely free from the complication of a further conception (Baldwin and Freestone, 1971; Sever, 1971) and the first-born child is unprotected. If the average family size is $2 \cdot 4$ children, then postpartum vaccination at best cannot protect more than $60 \%$ of at-risk births. It has sometimes been suggested that the first-born child is unlikely to suffer congenital rubella but $48 \%$ of affected children in the National Rubella Surveillance Programme (Dudgeon et al., 1973) are reported to be first-born. Furthermore, any reactions to vaccination appear nine to 10 days later at a time when maternity nursing services have been completed and the mother is left alone to cope with her newborn infant.

Rubella vaccines have been given to nursing staff (Marshall et al., 1971), women attending for treatment of infertility (Ingalls and Horne, 1971), and women attending family planning clinics (Tattersall and Freestone, 1973). Incentive is important in the last group. Women who are prepared to attend family planning clinics to avoid an unwanted pregnancy should be less likely to exhibit the complication of 'vaccination-associated pregnancy'.

Other efforts to avoid pregnancy have included vaccination during menstruation (Ingalls and Horne, 1971), although some women menstruate during the first months of pregnancy (Holland and Brews, 1969), and the use of medroxy progesterone as a depot contraceptive, but this drug produced some prolongation of postpartum vaginal bleeding (Sharp and MacDonald, 1973). Pregnancy tests have also been employed although they are chiefly of medicolegal importance (Freestone, Prydie, Hamilton Smith, and Laurence, 1971) and contribute little to the security of vaccination of adults. There appears to be no good substitute to limiting vaccination to 'good-risk' patients, a careful explanation of the hazards involved, and the prescription of a reliable method of contraception.

\section{Duration of Protection Produced by VACCINATION}

It is generally accepted that a single attack of rubella or measles confers lifelong immunity and similarly that live attenuated rubella and measles vaccines will probably provide protection of many years' duration. In no country at present do schedules allow for routine revaccination against either measles or rubella. In that these vaccines are those most recently developed, the duration of protection they provide has not been conclusively established and will only emerge from presently ongoing studies of antibody persistence. However, since in the United Kingdom and the United States current schedules for earlier developed live virus vaccines (smallpox, yellow fever, oral poliomyelitis) all give recommendations for revaccination, it seems prudent to admit that hopes for a single dose schedule for vaccination against rubella may not be realized. In the United States the implications of waning titres of vaccine-induced rubella antibody would be much more serious than in Britain since a longer duration of protection is required with vaccine given earlier in life. In the United Kingdom, the majority of girls have solid immunity resulting from natural infection and the minority are vaccinated at about puberty, so the consequences of waning antibody would be less significant. The United States programme of mass vaccination of young children with vaccines which give shortterm protection may only temporarily reduce the incidence of natural rubella to low levels, and may result in a new generation of young adults being particularly susceptible. This might arise if all children were not reached by vaccination, or as a result of waning vaccine-induced antibody in the absence of natural infection or revaccination procedures. It has been suggested that asymptomatic and aviraemic natural reinfection would boost vaccine-induced antibody and maintain protection, but this cannot occur if infection is eradicated. Furthermore, the occurence of reinfection is capricious, and one cannot rely on it to boost antibody titres when and in those in whom it is required without risk to the fetus. 
There is much to be said in favour of the British system whereby the number of rubella-susceptible females vaccinated is insufficient to interfere with the prevalence of natural infection among children but does not allow for susceptible women to be protected.

\section{VACCINATION FAILURES}

The many reports of clinical trials of rubella vaccines describe seroconversion rates varying from $95 \%$ to $100 \%$. It is clear that for a variety of reasons up to $5 \%$ of subjects may fail to respond to subcutaneous administration of vaccine. A proportion of these subjects may be protected against both vaccination and natural infection by local antibody, cellular immune mechanisms or by low titres of circulating antibody not detected by the currently used test procedures. However, in others, vaccination failure may result from a temporary increase in host resistance to infection, or inadvertent inactivation of vaccine due to the manufacturers' recommendations in relation to storage and reconstitution not being followed. Since in neither the United States nor the United Kingdom is vaccination of children serologically controlled, a small but numerically significant number of young women in both countries will incorrectly believe themselves to be protected against rubella. There is a risk that such women may fail to obtain medical advice and appropriate investigation on exposure to natural rubella or on infection.

\section{Rubella Vaccine Strains}

Plotkin has described differences between the Wistar RA 27/3 and the HPV 77 DE 5 and Cendehill strains of rubella vaccine (Plotkin, Farquhar, and Ogra, 1973). The Wistar strain appears to elicit higher titres of circulating antibody (Andzhaparidze, Desyatskova, Chervonski, and Pryanichnikova, 1970; Fogel, Moshkowitz, Rannon, and Gerichter, 1971; Hutchinson, Cowburn, and Fairfax, 1971) and a broader range of circulating antibody responses (Le Bouvier and Plotkin, 1971; Wallace and Isacson, 1972; Lalla, Vesikari, and Virolainen, 1973). In contrast to the other strains, the Wistar strain induces local nasal IgA antibody, which is of an even higher order after intranasal administration of the vaccine. These characteristics appear to correlate with a greater resistance to infection (Plotkin et al., 1973). In addition, the Wistar strain appears to be the exception to the rule that there is a linear relationship between immunogenicity and reactogenicity.
In children, there seems to be little difference in the incidence and severity between the three strains (Andzhaparidze et al., 1970; Hutchinson et al. 1971; Wallace and Isacson, 1972). However, in adults the concensus of available results is that the HPV 77 DE 5 strain is the most reactogenic, at least in relation to the occurrence of joint symptoms, while the RA $27 / 3$ strain is somewhat more reactogenic than the Cendehill strain (Dudgeon, Marshall, Peckham, and Hawkins, 1969; Sharp and MacDonald, 1973; Lalla et al., 1973; Grillner et al., 1973).

It seems possible that these characteristics of the Wistar RA 27/3 strain may assume greater importance in the years ahead. However, whether they are sufficient to allow the aim of eradication of rubella in the United States to be attained will be established only by studies in the future with longer intervals between vaccination and challenge.

I gratefully acknowledge comments and criticism of this manuscript by Dr. A. H. Griffith.

\section{REFERENCES}

andzhaparidze, O. G., Desyatskova, R. G., Chervonski, G. I., and Pryanichnikova, L. V. (1970). Immunogenicity and reactogenicity of live attenuated rubella virus vaccines. Amer. J. Epidem., 91, 527.

Baldwin, J. A. and Freestone, D. S. (1971). Risk of early post-partum pregnancy in context of postpartum vaccination against rubella. Lancet, 2, 366.

Beazley, J. M., Hurley, R., Middlebrook, C., and RUMPUS, M. F. (1971). Rubella vaccination in the puerperium. Brit. J. prev. soc. Med., 25, 140.

Chang, T. - W., Desrosiers, S., and Weinstein, $L$. (1970). Clinical and serologic studies of an outbreak of rubella in a vaccinated population. New Engl. J. Med., 283, 246.

COCKBURN, W. C. (1969). World aspects of the epidemiology of rubella. Amer. J. Dis. Child., 118, 112.

COOPER, L. Z., Ziring, P. R., OCKerse, A. B., Fedun, B. A., Kiely, B., and Krugman, S. (1969). Rubella: clinical manifestations and management. Amer. J. Dis. Child., 118, 18.

Davis, W. J., larson, H. E., Simsarian, J. P., Parkman, P. D., and MEYER, H. M. (1971). A study of rubella immunity and resistance to infection. J. Amer. med. Ass., 215, 600.

Department of Health and Social Security (1972). Immunisation Against Infectious Disease, p. 9. HMSO, London.

(1971-73). Annual Reports for 1970, 1971 and 1972. HMSO, London. 
Dudgeon, J. A., Marshall, W. C., Peckham, C. S., and Hawkins, G. T. (1969). Clinical and laboratory studies with rubella vaccines in adults. Brit. med. J., 1, 271.

-, Peckham, C. S., Marshall, W. C., Smithells, R. W., and SHEPPARD, S. (1973). National congenital rubella surveillance programme. Health Trends, 5, 75.

Evans, A. S., Niederman, J. C., and Sawyer, R. N. (1971). Prospective studies of a group of Yale University Freshmen. II. Occurrence of acute respiratory infections and rubella. J. infect. Dis., 123, 271.

FARQUHAR, J. D. (1973). Experience with rubella and rubella immunization in institutionalized children. J. Pediat., 83, 51.

Field, A. M. (1967). The occurrence of neutralizing and complement fixing antibodies in rubella. J. Hyg. (Camb.), 65, 409.

Fogel, A., Moshrowitz, A., Rannon, L., and GERICHTER, Ch.B. (1971). Comparative trials of RA $27 / 3$ and Cendehill rubella vaccines in adult and adolescent females. Amer. J. Epidem., 93, 392.

Freestone, D. S., Prydie, J., Hamilton Smith, S. G., and LAURENCE, G. (1971). Vaccination of adults with Wistar RA 27/3 rubella vaccine. J. Hyg. (Camb.), 69, 471.

Grillner, L., Hedstrom, C. E., Bergstrom, H., ForSSMAN, L., Rigner, A., and LYCKe, E. (1973). Vaccination against rubella of newly delivered women. Scand. J. infect. Dis., 5, 237.

HollaNd, E. and BRews, A. (1969). Manual of Obstetrics. 13th ed., edited by R. Percival. Churchill, London.

Horstmann, D. M., Liebhaber, H., Le Bouvier, G. L., Rosenberg, D. A., and Halstead, S. B. (1970a). Rubella: reinfection of vaccinated and naturally immune persons exposed in an epidemic. New Engl. J. Med., 283, 771.

$\longrightarrow$, - and KoHorN, E. I. (1970b). Post-partum vaccination of rubella-susceptible women, Lancet, 2, 1003.

Hutchinson, D. N., Cowburn, G. R., and Fairfax, C. F. W. (1971). Rubella vaccination of non-immune schoolgirls and young women. Community Medicine, 126, 225.

INGALLS, T. H. and HoRNE, H. W. Jr. (1971). Immunisation of women with rubella (RA 27/3) vaccine administered intranasally. Lancet, 1, 830.

Judelsohn, R. G. and WyLL, S. A. (1973). Rubella in Bermuda. J. Amer. med. Ass., 223, 401.

KLOCK, L. E. and RACHELEFSKY, G. S. (1973). Failure of rubella herd immunity during an epidemic. New Engl. J. Med., 288, 69.

Krugman, S. and Perkins, F. T. (1973). Vaccination against communicable diseases. Amer. J. Dis. Child., 126, 406.
Lalla, M., Vesikari, T., and Virolainen, M. (1973). Lymphoblast proliferation and humoral antibody response after rubella vaccination. Clin. exp. Immunol., 15, 193.

Le Bouvier, G. L. and Plotrin, S. A. (1971). Precipitin responses to rubella vaccine RA 27/3. J. infect. Dis., 123, 220.

Lehane, D. E., Newberg, N. R., and Beam, W. E. (1970). Evaluation of rubella herd immunity during an epidemic, J. Amer. med. Ass., 213, 2236.

Marshall, W. C., Peckham, C. S., Darby, C. P., Dudgeon, J. A., and Hawkins, G. T. (1971). Further studies with rubella vaccines in adults and children. Practitioner, 207, 632.

Phillips, C. A., Maeck, J. van S., Rogers, W. A., and SAVEL, H. (1970). Intrauterine rubella infection following immunization with rubella vaccine. J. Amer. med. Ass., 213, 624.

Plotkin, S. A., Farquhar, J. D., and Ogra, P. L. (1973). Immunologic properties of RA 27/3 rubella virus vaccine. A comparison with strains presently licensed in the United States. J. Amer. med. Ass., 225, 585.

Rawls, W. E., Melnick, J. L., Bradstreet, C. M. P., Bailey, M., Ferris, A. A., LehmanN, N. I., Nagler, F. P., Furesz, J., Kono, R., Ohtawara, M., halonen, P., Stewart, J., Ryan, J. M., Strauss, J., Zdrazilek, J., Leerhoy, J., voN MAGNUS, H., SOHIER, R., and FERREIRA, W. (1967). WHO Collaborative Study on the sero-epidemiology of rubella. Bull. Wld Hlth Org., 37, 79.

SAIDI, S. (1972). Epidemiological survey of rubella immunity in Iran. Bull. Wld Hlth Org., 46, 563.

SEVER, J. L. (1971). Rubella immunization risk postpartum. J. Amer. med. Ass., 217, 697.

Sharp, D. S. and Macdonald, H. (1973). Use of medroxyprogesterone acetate as a contraceptive in conjunction with early postpartum rubella vaccination. Brit. med. J., 4, 443.

TatTersall, J. M. and Freestone, D. S. (1973). Rubella vaccination in young women attending a family planning clinic. Practitioner, 211, 769.

ToBrN, J. O. H. (1971). Rubella vaccination of post partum women and of adolescents in the Northwest of England. Canad. J. publ. Hlth, Monograph Supplement, 62, p. 64.

United States Department of Health, Education AND Welfare (1972). Collected Recommendations of the Public Health Service Advisory Committee on Immunisation Practices. Morbidity and Mortality, 21, Supplement, p. 23.

(1973). Public Health Service. Rubella, Measles, Polio Immunization Status Report No. 20. Government Printing Office, Washington. 
Vaheri, A., Vesirari, T., Oker-Blom, N., Seppala, M., Parkman, P. D., Veronelli, J., and Robbins, F. (1972). Isolation of attenuated rubella-vaccine virus from human products of conception and uterine cervix. New Engl. J. Med., 286, 1071.

VesiKARI, T. (1972). Antibody response in rubella reinfection. Scand. J. infect. Dis., 4, 11.

Wallace, R. B. and Isacson, P. (1972). Comparative trial of HPV-77, DE-5 and RA 27/3 live attenuated rubella vaccines. Amer. J. Dis. Child., 124, 536.

Wilkins, J., Leedom, J. M., Portnoy, B., and SALVATORE, M. A. (1969). Reinfection with rubella virus despite live vaccine induced immunity. Amer. J. Dis. Child., 118, 275.

WyLl, S. A. and HerrmanN, K. L. (1973). Inadvertent rubella vaccination of pregnant women. J. Amer. med. Ass., 225, 1472. 